\section{Risk factors for third- and fourth-degree perineal tears during vaginal delivery}

\author{
Leonard Juul, Gerhard B. Theron \\ Department of Obstetrics and \\ Gynaecology, Tygerberg Hospital \\ University of Stellenbosch, Cape Town, \\ South Africa
}

\section{Abstract}

Objective. To identify risk factors for thirdand fourth-degree perineal tears, so as to anticipate and intervene in order to prevent this complication that can severely affect a woman's quality of life. The study design was a retrospective case control study.

Method. Ninety-three cases of third- and fourth-degree perineal tears were identified from the birth register of a tertiary referral hospital (Tygerberg Hospital). One hundred and nine patients with normal vaginal deliveries in the same time period were used as control group.

Results. An analysis of the results revealed that there were no significant differences between cases and controls with regards to age, body mass index (BMI), gestation at delivery, duration of second stage, episiotomy and birth weight. However, there were significantly more primigravidas, assisted deliveries (forceps and vacuum), occipitoposterior positions, HIV negative patients and shoulder dystocia in the study group.

Conclusions. Antenatal risk factors for thirdand fourth-degree tears are difficult to identify. However, intrapartum occipitoposterior and assisted deliveries, especially in the primigravid patient, should warn the obstetrician/ midwife about the risk of a severe tear. A restrictive episiotomy policy should be practiced. Shoulder dystocia was invariably associated with third- and fourth-degree tears in this study. The higher incidence of HIV negative patients in the study group requires further research.

\section{Introduction}

Perineal trauma during child birth is very common, occurring in about $40 \%$ of women during their first birth and about $20 \%$ in subsequent births. ${ }^{1}$ Any laceration involving more than the perineal skin and the subcutaneous tissue must be regarded as an obstetric complication. ${ }^{2}$ Lacerations involving the perineal and other vulvar muscles, resulting in rectal incon- tinence and sexual dysfunction, have a major impact on the quality of life of the patient and should be avoided where possible. ${ }^{2}$ Severe perineal tears which involve the anal sphincters and/or the rectal mucosa are identified in 0.6$0.9 \%$ of vaginal deliveries. ${ }^{3}$ Most published literature on perineal trauma come from developed countries and there is limited information from developing countries.

Perineal lacerations occur during delivery of the head and shoulders of the fetus. During a normal vertex delivery it must be taken into account that the final step in the mechanism of normal birth is that of extension of the fetal head. Therefore, it is recommended that the perineum should be supported during the process of gradual stretching, and the presenting part must be assisted in extension. ${ }^{2}$ Recognized risk factors for perineal lacerations include maternal factors (precipitate labour and very narrow introitus), fetal factors (large fetus, occipitoposterior position and abnormal presentation) and obstetric care factors (uncontrolled/precipitate delivery, assisted deliveries, maldirected episiotomy, extended episiotomy by tearing), ${ }^{1,3-5}$

It is proposed that the following Royal College Guideline is used. ${ }^{3}$

Degrees of perineal lacerations should include lacerations of skin and superficial subcutaneous tissues (grade 1), the skin, perineal body and muscles (grade 2) and the skin, perineal body and muscles, and the anal sphincter complex (external and internal anal sphincter): (grade 3 ).

$3 \mathrm{a}$ : less than $50 \%$ of external anal sphincter thickness (EAS) torn

$3 \mathrm{~b}$ : more than $50 \%$ of external anal sphincter (EAS) thickness torn

3c: internal anal sphincter (IAS) torn

Fourth degree: injury to perineum involving the anal sphincter complex (EAS and IAS) and rectal mucosa. It has also been proposed to include a fifth type of tear (button-hole tear) in which the anal sphincter is intact but the anal mucosa is torn. ${ }^{6}$

With this study our aim was to identify the risk factors specifically applicable to the patient population of a referral hospital in the Western Cape, South Africa (Tygerberg Hospital) and possibly also to recognize additional risk factors.

In our unit uncomplicated vaginal deliveries are conducted by midwives, but assisted deliveries are conducted by Registrars or Medical Officers under the supervision of a Consultant Obstetrician. A selective policy of mediolateral episiotomies is applied at our institution.

Identification of risk factors for third- and fourth-degree perineal tears will allow anticipation and intervention in order to prevent this complication that can severely affect a woman's quality of life.
Correspondence: Leonard Juul, Department of Obstetrics and Gynaecology, Tygerberg Hospital, University of Stellenbosch, Francie Van Zijl, Cape Town 7505 , South Africa.

Tel. +27.21.9384289.

E-mail: ljuul@telkomsa.net

Key words: medicine, obstetrics, perineal tears.

Received for publication: 31 January 2011.

Revision received: 23 May 2011.

Accepted for publication: 30 June 2011.

This work is licensed under a Creative Commons Attribution NonCommercial 3.0 License (CC BYNC 3.0).

CCopyright L. Juul and G.B. Theron, 2011

Licensee PAGEPress, Italy

Urogynaecologia 2011; 25:e2

doi:10.4081/uij.2011.e2

\section{Design and Methods}

This was retrospective case control study. The birth register at a tertiary referral hospital was used in order to identify about 100 consecutive cases of third- and fourth-degree perineal tears following vaginal delivery. This was done retrospectively from the date of commencement of the study. About 100 patients with a normal vaginal delivery at term in the same time period were selected in order to serve as control group. The first patient in birth register after study patient, with normal term vaginal delivery was selected as control. All vaginal deliveries, including breech deliveries and multifetal pregnancies, qualified for inclusion in the study.

Comparing women with third- and fourthdegree tears (study patients) and those without (control patients) regarding: birth weight over $4 \mathrm{~kg}$, mean and median birth weight, nulliparity, maternal body mass index, induction of labour, occipitoposterior position, epidural analgesia, duration of second stage in minutes, episiotomy, ${ }^{7}$ forceps delivery, ventouse delivery, duration of hospital stay of mothers and babies, wound sepsis, oxytocin use and born before arrival.

The study and control patients were compared with regards to outcome. Qualitative data with the $\chi^{2}$ and Fischer's exact test with small numbers. Quantitative data with a normal distribution with the Student's t-test and when the distribution was not normal with the Mann Whitney u-test. Sample size was calculated, using a power of $80 \%$ and alpha value of $5 \%$, to identify risk factors that occurred with a frequency of $20 \%$ in the study group and $5 \%$ in the control group as significant. A total of 79 patients were required in each of the study and control arms of the study. 
The study was a file review and the information extracted from files was transferred to data sheets anonymously. Ethical approval was obtained from the Committee for Human Research of the Faculty of Health Sciences, Stellenbosch University.

\section{Results}

During the study period from January 2000 to January 2006, a total of 134 patients with third- and fourth-degree tears were identified in the birth register of which 93 patients had sufficient information. Some patients' files could not be found or the patient numbers were written incorrectly in the birth register. We also identified 109 controls in which the necessary information was available. During this time there were 31,665 deliveries at our facility of which $74 \%$ were vaginal deliveries. This equates to $0.6 \%$ of our patients suffering a third- and fourth-degree perineal tear after vaginal delivery.

There was a breech delivery in both the study and control arm, with no multifetal pregnancies and all remaining patients had vertex presentations.

There was a significant association $(\mathrm{P}=0.007)$ between low parity and perineal tears (Table 1). Specifically, when comparing patients with regards to primiparity in this study, $52.7 \%$ of the study group, compared to $37.6 \%$ of the controls were primiparous $(\mathrm{P}=0.03)$.

Assisted/instrumental deliveries were employed in $19.6 \%$ of the study group, compared to none in the control group (Table 2).

Sixteen deliveries (17.20\%) in the study was complicated by occipitoposterior positions, compared to $5.5 \%$ of those in the control group (Table 3).

In this study $5.56 \%$ of deliveries in the study group being complicated by shoulder dystocia, compared to none in the control group (Table 4). Only $13.1 \%$ of patients in the study group were HIV positive, compared to $32.9 \%$ in the control group. The average baby's birth weight of the HIV positive study patients was $3514 \mathrm{~g}$ compared to $3178 \mathrm{~g}$ of the HIV positive controls (Table 5, $\mathrm{P}=0.09$ ). The average hospital stay in the study group was 3.7 days compared to 1.98 days in the control group. Epidurals were used in $3.3 \%$ of the study group and $3.7 \%$ in the control group.

In this study we could not find any significant associations with anal sphincter injury and any of the following factors: age, BMI, gestation at delivery, duration of the second stage lasting more than one hour, oxytocin use, episiotomy and birth weight. The episiotomy rate during this study was $36.4 \%$ in the study group and $36.8 \%$ in the control group.
Fifteen of 91 tears were sutured in labour ward. Antibiotics and laxatives were prescribed in $97.8 \% 84.4 \%$ of study patiens, respectively. $78.9 \%$ of study patients were prescribed Sitz baths. Analgesics were prescribed in $3.4 \%$ of study patients.

Registrars sutured 58 of the tears, 24 were sutured by consultants and 9 by midwives.

\section{Discussion}

These results confirm the difficulty in predicting tears. Certain known risk factors were shown to be applicable on our study population, namely: first delivery (Table 1), assisted deliveries (Table 2), occipitoposterior position (Table 3) and shoulder dystocia (Table 4). The risk is increased between two- and fivefold, which reflects the reduced elasticity of the pelvic floor among nulliparas. ${ }^{8}$ The index study confirms this finding.

The percentage $(0.6 \%)$ of third- and fourthdegree perineal tears identified compares well to the $0.6-0.9 \%$ reported in the literature. ${ }^{3}$

Instrumental delivery is an integral part of obstetrics, and although it reduces the Caesarean section rate, maternal morbidity is higher than that following unassisted delivery. The Cochrane Review has concluded that the use of the vacuum extractor rather than forceps appears to reduce maternal morbidity, although the reduction in cephalohaematoma and retinal haemorrhages seen with forceps may be a compensatory benefit. ${ }^{9}$ Soft cups are significantly more likely to fail compared to metal cups, since their ability to improve flexion and facilitate rotation is less. Although soft cups were associated with less scalp injury, there was no difference compared to metal cups in terms of maternal morbidity. ${ }^{9}$ In this study metal cups were mostly used. Due to the retrospective nature of the study, it was not always possible to ascertain whether a soft or metal cup was used. An important research question would be to randomize patients who met the criteria for an outlet forceps delivery with a Wrigley's forceps into soft cup vacuum extractions and forceps deliveries groups. Maternal and neonatal morbidities could then be compared more fairly. Malposition, particularly the persistent occipitoposterior position, has a larger presenting diameter and is associated with anal sphincter injury. ${ }^{4}$ This was confirmed in our study (Table 5).

Carroli and Belizan (1999) reviewed the Cochrane Pregnancy and Childbirth Group trials registry..$^{10}$ There were six randomized trials of nearly 5000 deliveries in which routine (73\% rate) vs restricted (28\% rate) use of episiotomy was evaluated. There were lower rates of posterior perineal trauma, surgical repair, and healing complications in the restricted- use group. Alternatively, the incidence of anterior perineal trauma was lower in the routine use group. It seems reasonable to conclude that that episiotomy should not be performed routinely. ${ }^{11}$ The procedure should be applied selectively in instances where it is obvious that failure to perform an episiotomy will result in perineal rupture. ${ }^{12}$ It has been suggested that the ideal rate of episiotomy should be no more than $20-30 \% .{ }^{6}$ The episiotomy rate during this study was $36.4 \%$ in the study group and $36.8 \%$ in the control group. The episiotomy rate at Tygerberg Hospital could be explained by the high risk nature of patients managed at a tertiary hospital.

There was not a universally agreed upon staging system for perineal tears at our institution at the time of this project. The result was that all tears were empirically classified as third degree tears. This is something that was addressed as a result of this study and we now use the classification as proposed by the RCOG.

Few patients had epidurals as we have limited personnel available to perform and especially monitor epidurals. Epidurals were only provided where it was medically indicated.

A surprising finding was the association of HIV negativity in the study population compared to controls (Table 5). An explanation could be the reluctance in cutting an episiotomy in HIV positive patients, based on the higher rate of vertical transmission associated with episiotomies. ${ }^{13}$ The restrictive use of episiotomies could thus have inadvertently protected these patients against posterior perineal trauma. ${ }^{10}$ Interpretation is limited by the number of patients with known HIV status since this study's start date was before routine HIV testing was implemented. Southern Africa is the epicenter of the global HIV pandemic. During the study period, the national HIV prevalence amongst pregnant women in the public sector ranged from $26-29 \%$. The national HIV protocol does not recommend routine cesarean sections before the onset of labour. The available health care infrastructure also does not have the capacity to do this,

Factors that are mentioned in the literature, but that were not found to be significant in this study population include: age, BMI, gestation at delivery, duration of the second stage, oxytocin use, episiotomy and birth weight (Table 6). Of importance, here is the use of oxytocin, which was not associated with tears. One can hypothesize that if oxytocin was used more liberally, especially in primigravidas the rate of tears could be safely reduced. ${ }^{1,6}$ The first phase of the second stage of labour, particurly in women who have an epidural, would then be accelerated, thus obviating the need to resort to instrumental delivery. Interestingly it was found that in both study and control group the birth weight was quite similar (study $3295 \mathrm{~g}$; 
control 3216 g). Patients with frank macrosomia would probably have been identified earlier in labour due to poor progress and cephalopelvic disproportion and delivered by Cesarean section. The Apgar scores with an average of 9.3 in the study group and 9.4 in the control group respectively, indicates that the neonatal outcome between the groups did not differ. It is recommended that tears should be repaired in theatre (level IV evidence), where there is access to good lighting, appropriate equipment and aseptic conditions. ${ }^{3}$ General or regional anaesthesia is an important prerequisite as muscle relaxation is necessary to retrieve the muscle ends, especially if it is intended to do an overlap repair. ${ }^{6}$ The most experienced surgeon available should do or supervise the repair and we have, subsequent to this study, discouraged the suturing of these tears by midwives or inexperienced, unsupervised doctors. There is insufficient data as far as the methods of repair is concerned, but the overlap technique appeared to be better in terms of faecal urgency and incontinence, compared to the end-to-end technique. ${ }^{14}$ There are insufficient data regarding the type of suturing material, but monofilament suture material (PDSTM) appears to be better than catgut or braided polyglactin (VicrylTM) in the repair the sphincter because of a longer half life and a lower likelihood of infection. ${ }^{15}$ The issue of antibiotic prophylaxis for fourthdegree perineal tears during vaginal delivery has been subjected to a Cochrane Review, but no trials were found that met the selection criteria. ${ }^{16}$ Although firm evidence is scanty, it appears likely that prophylactic antibiotics enhances the integrity of the sphincter repair and prevents infection. ${ }^{1}$ On the other hand firm randomized, controlled data exist to support the use of a laxative rather than a constipating postoperative regimen during the early puerperium. ${ }^{17}$ The low percentage $(3.41 \%)$ of patients receiving analgesia should be addressed. As shown by the Cochrane Review, NSAID rectal analgesia should be promoted. ${ }^{18}$ There is a lack of research regarding the use of Sitz baths after perineal repair, but logic would dictate that keeping the operative site as free from contamination as possible would promote healing.

These patients should be followed up with a bowel function questionnaire, gynaecologic examination, with special attention to anal sphincter function (pinch action) and sensation in the pudendal nerve distribution on the skin. Anal incontinence could still develop 6-12 months later and women should be informed about this possibility.

Subsequent vaginal delivery may worsen anal incontinence symptoms. ${ }^{19}$ Therefore, in clinical practice the focus should be on symptomatic patients or those with abnormal endoanal ultrasonography or manometry, in whom the option of elective caesarean section should be discussed. ${ }^{3}$ In asymptomatic patients there is no clear evidence as to the mode of delivery. A previous successful secondary sphincter repair, as opposed to a successful primary repair, should be managed with a prelabour caesarean section. ${ }^{1}$

\section{Conclusions}

The results confirm the difficulty in predicting shoulder dystocia, but the neonatal outcome in this study seemed generally to be good. It is recommended that the possibility of third- and fourth-degree tears in the nulliparous, with assisted deliveries and with persistent OP positions should be anticipated. This is especially true when these factors are

Table 1. Gravidity and parity.

\begin{tabular}{|c|c|c|c|c|c|c|}
\hline & n Avg & Std & Vedian & & & \\
\hline $\begin{array}{l}\text { Gravidity } \\
\text { (Study } \\
\text { group) }\end{array}$ & $\begin{array}{ll}93 & 1.8\end{array}$ & 1.1 & 1 & 1 & 6 & \\
\hline $\begin{array}{l}\text { Gravidity } \\
\text { (Control } \\
\text { group) }\end{array}$ & 1092.3 & 1.4 & 2 & & $\theta$ & \\
\hline $\begin{array}{l}\text { Parity } \\
\text { (Study } \\
\text { group) }\end{array}$ & $\begin{array}{ll}93 & 0.7\end{array}$ & 0.9 & 0 & 0 & 5 & 0. \\
\hline $\begin{array}{l}\text { Parity } \\
\text { (Control } \\
\text { group) }\end{array}$ & 1091.1 & 1.1 & 1 & 0 & 4 & \\
\hline
\end{tabular}

Table 2. Method of delivery.

\begin{tabular}{lcc} 
& Study & Control \\
$\mathrm{n}$ & 93 & 109 \\
$\mathrm{NVD}$ & $71(76.3 \%)$ & $108(99.0 \%)$ \\
\hline
\end{tabular}

\begin{tabular}{lcc}
\hline Breech & 1 & 1 \\
Forceps & 3 & 0 \\
\hline Vacuum & 18 & 0 \\
\hline
\end{tabular}

$\mathrm{P}<0.001$.

Table 3. Occipitoposterior position.

\begin{tabular}{lcc} 
& Study & Control \\
$\mathrm{n}$ & 85 & 105 \\
Yes & $16(17.2 \%)$ & $6(5.5 \%)$ \\
\hline No & 69 & 99 \\
\hline $\mathrm{P}<0.005$. & &
\end{tabular}

Table 4. Shoulder dystocia.

\begin{tabular}{lcc} 
& Study & Control \\
$\mathrm{n}$ & 86 & 104 \\
Yes & $5(5.56 \%)$ & 0 \\
\hline No & 81 & 104 \\
\hline $\mathrm{P}<0.005$. & &
\end{tabular}

combined. The routine use of episiotomies in these patients, would probably be justified. These patients should be meticulously examined for possible tears and a uniform classification system should be applied. Oxytocin should be used in the first stage of labour to correct poor progress due to inadequate or dysfunctional uterine contractions. This will lead to decreased occipitoposterior positions and assisted deliveries.

Vacuum extraction should be the first choice for low-cavity instrumental delivery. Prophylactic antibiotics and stool softeners are recommended. Follow-up should be scheduled 8-12 weeks later in order to evaluate sphincter function. We conclude that further studies with larger numbers are needed in order to better identify predisposing factors for third- and fourth-degree tears. We also would recommend a systematic review of the available studies.

Table 5. HIV.

\begin{tabular}{lcc} 
& Study & Control \\
$\mathrm{n}$ & 61 & 73 \\
Positive & $8(13.1 \%)$ & $24(32.9 \%)$ \\
\hline Negative & 53 & 49 \\
$\begin{array}{l}\text { Average weight } \\
\text { in HIV+ patients }\end{array}$ & $3514 \mathrm{~g}$ & $3178 \mathrm{~g}$ \\
\hline
\end{tabular}

$\mathrm{P}=0.008$ (for HIV+); $\mathrm{P}=0.09$ (for average birth weight in HIV+ patients)

Table 6. Summary data.

\begin{tabular}{|c|c|c|c|c|c|c|}
\hline & n & Avg & Std & Median & Min & Max $P$ \\
\hline $\begin{array}{l}\text { Age } \\
\text { (Study } \\
\text { group) }\end{array}$ & 93 & $\begin{array}{c}24.0 \\
\text { years }\end{array}$ & 5.4 & 24 & 14 & $42 \quad 0.08$ \\
\hline $\begin{array}{l}\text { Age } \\
\text { (Control } \\
\text { group) }\end{array}$ & 109 & $\begin{array}{c}25.6 \\
\text { years }\end{array}$ & 6.9 & 25 & 15 & 42 \\
\hline $\begin{array}{l}\text { BMI } \\
\text { (Study } \\
\text { group) }\end{array}$ & 64 & 27.5 & 5.8 & 26.9 & 15.9 & 42.80 .21 \\
\hline $\begin{array}{l}\text { BMI } \\
\text { (Control } \\
\text { group) } \\
\end{array}$ & 83 & 28.9 & 7.6 & 27.2 & 16.7 & 50.1 \\
\hline $\begin{array}{l}\text { Gestational } \\
\text { age at } \\
\text { delivery } \\
\text { (Study } \\
\text { group) }\end{array}$ & 91 & $\begin{array}{c}39.3 \\
\text { weeks }\end{array}$ & 2.3 & 40 & 33 & $\begin{array}{ll}44 & 0.99\end{array}$ \\
\hline $\begin{array}{l}\text { Gestational } \\
\text { age at } \\
\text { delivery } \\
\text { (Control } \\
\text { group) }\end{array}$ & 109 & $\begin{array}{c}39.3 \\
\text { weeks }\end{array}$ & 1.6 & 39 & 35 & 42 \\
\hline $\begin{array}{l}\text { Birth } \\
\text { weight } \\
\text { (Study } \\
\text { group) }\end{array}$ & 93 & 3295 & 503.1 & 3220 & 1890 & 45080.27 \\
\hline $\begin{array}{l}\text { Birth weight } \\
\text { (Control } \\
\text { group) }\end{array}$ & 108 & $\begin{array}{c}3216.3 \\
\mathrm{~g}\end{array}$ & 502.8 & 3200 & 2186 & 4484 \\
\hline
\end{tabular}




\section{Refrences}

1. James DK, Steer PJ, Weiner CP, Gonik B. High Risk Pregnancy Management Options, 3rd ed. 2005, Saunders Elsevier, Amsterdam, The Netherlands.

2. Grobler CJF, Cronje HS. Obstetrics in Southern Africa. 2003, Van Schaik, Hatfield, South Africa.

3. Royal College of Obstetricians and Gynaecologists (RCOG). The management of third- and fourth-degree perineal tears (green-top 29). Available from: http://www.rcog.org.uk/womens-health/ clinical-guidance/management-third-andfourth-degree-perineal-tears-green-top-29

4. de Leeuw JW, Struijk PC, Vierhout ME, Wallenburg HC. Risk factors for third degree perineal ruptures during vaginal delivery. BJOG 2001;108:383-7.

5. Dahlen HG, Ryan M, Homer CSE, Cooke M. An Australian prospective cohort study of risk factors for severe perineal trauma during childbirth. Midwifery 2007;23:196203.

6. Fernando JF, Sultan AH. Risk factors and management of obstetric perineal injury. Curr Obstet Gynaecol 2004;14:320-6.

7. Fernando RJ, Sultan AH, Radley S, et al. Management of obstetric anal sphincter injury - the way forward. Proceedings 29th British Congress of Obstetrics and Gynaecology, Birmingham, UK, July 2001, Abstract 347.

8. Donnely VS, Fynes M, Campbell DM, et al. Obstetric events leading to anal sphincter damage. Obstet Gynecol 1998;92:955-61.

9. Johanson RB, Menon BKV. Soft versus rigid vacuum extractor cups for assisted vaginal delivery. In: The Cochrane Library, Issue 4, 2003. Oxford

10. Carroli G, Belizan J. Episiotomy for vaginal birth. Cochrane Database Syst Rev 1997;2:CD000081.

11. Eason E, Feldman P. Much ado about a little cut: Is episiotomy worthwile? Obstet Gynecol 2000;95:616-8.

12. Cunningham FG, Leveno KJ, Bloom SL, et al. Williams Obstetrics, 22nd ed. 2005, McGraw-Hill, New York, NY, USA.

13. European Collaborative Study. Risk factors for mother-to-child transmission of HIV-1. Lancet 1992;339:1007-12.
14. Fernando JF, Sultan AH, Kettle C, et al. Methods of repair for obstetric anal sphincter injury. Cochrane Database Syst Rev 2006;3:CD002866.

15. Sultan AH, Monga AK, Kumar D, Stanton SL. Primary repair of obstetric anal sphincter rupture using the overlap technique. $\mathrm{Br}$ J Obstet Gynaecol 1999;106:318-23.

16. Buppasiri P, Lumbiganon P, Thinkhamrop J, Thinkhamrop B. Antbiotic prophylaxis for fourth-degree perineal tear during vaginal birth. Cochrane Database Syst Rev 2010;11:CD005125.

17. Mahony R, Behan M, O'Herlihy C, O'Connell PR. Randomized, clinical trial of bowel confinement vs laxative use after primary repair of third-degree obstetric anal sphincter tear. Dis Colon Rectum 2004;47:12-7.

18. Fynes M, Marshall K, Cassidy M, et al. A randomized control trial on the effect of biofeedback therapy on anorectal physiology and faecal continence. Dis Colon Rectum 1999;42:753-8.

19. Jorge JM, Wexner SD. Aetiology and management of faecal incontinence. Dis Colon Rectum 1993;36:77-9. 